\title{
sciendo
}

ISSN: $1231-4005$

e-ISSN: $2354-0133$

DOI: $10.2478 /$ kones-2019-0103

\section{APPLICATION OF SIMILARITY METHOD OF DISTANCE COURSES DESCRIBING THE ELEMENTS CONTENT IN CEMENT CONCRETE AFTER 50 FORCED THERMAL CYCLES}

\author{
Małgorzata Linek \\ Kielce University of Technology \\ Faculty of Civil Engineering and Architecture \\ Department of Transportation Engineering \\ Tysiaclecia Państwa Polskiego Street 7, 25-314 Kielce, Poland \\ tel.: +48413424844 \\ e-mail:linekm@tu.kielce.pl
}

\begin{abstract}
The article presents material solution based on the application of ceramic dust as concrete mix component intended for airfield pavements. The applied dust influences the changes in internal structure of concrete composite. Diversification of internal microstructure of cement concrete using the suggested dust has significant influence on the improvement of compressive strength. The laboratory analyses included concretes curing in standard conditions and concretes subject to thermal cycles representing the destructive influence of imposed loading. Comparative SEM observations of concretes subject to 50 thermal cycles proved significant influence of dust on internal structure of composite. In the study 6 samples were selected, which, each time, were intended for the laboratory tests. The applied similarity analysis of distance courses in case of this concrete. Similarity indexes between input and target sequence were defined. Diagrams presenting the similarity of the analysed concretes were prepared (after 28 days of curing and after 50 thermal cycles). It was proved that the suggested method can be used to assess the elements content and define the similarity of concrete intended for airfield pavements in the selected of areas (cement matrix, contact area between fine aggregate and cement matrix, contact area between coarse aggregate and cement matrix and contact area between air voids and cement matrix).
\end{abstract}

Keywords: cement concrete, airfield pavement, analysis of similarity, forced thermal cycles

\section{Purpose and scope of the research}

The purpose of this publication has been the assessment of an opportunity to apply the analysis of similarity of distance courses with respect to cement concrete intended for airfield pavements. The scope of works consisted of two stages. During the first stage, the series of cement concrete were prepared. The analysis included cement concrete intended for airfield pavements, in compliance with [5] requirements. Ceramic additive as the substitute for the part of fine aggregate was used in concrete composition. This modifier was distinguished by different properties from fine aggregate (absorbability, physical and chemical characteristics, resistance to high temperature). The influence of forced thermal loads on the selected features of hardened concretes was assessed.

In the course of laboratory tests, the parameters of concrete mixes and hardened concrete were determined, after 28 days of concrete curing $[8,9]$. During scientific research, the amount of the required samples was determined using student's T-distribution assuming the significance level of 0.05 . The minimum essential number of samples ranged between 4 and 5 , depending on the type of the conducted test. In case of such assumptions, 6 samples were selected, which, each time, were intended for the laboratory tests.

Compression strength $\left(f_{c}\right)$ [10] in case of hardened concrete was determined. The size of the test samples was $150 \times 300 \mathrm{~mm}$. Samples size and the loading method were consistent with the requirements of [9]. The samples were positioned centrically in the durometer, which complied with the requirements of [10]. Load speed applied to the sample during the test was $0.5 \mathrm{MPa} / \mathrm{s}$. 
In the course of the test, maximum load value was determined. The concrete sample is capable to transfer the load before it is damaged.

Concrete compressive strength $\left(f_{c}\right)$ was determined according to formula (1) in which $F$ refers to maximum load applied to the sample $[\mathrm{N}], A_{c}$ - cross-sectional area of the sample $[\mathrm{mm}]$.

$$
f_{c}=\frac{F}{A_{c}} .
$$

Laboratory tests assumed the diversified number of thermal test cycles. A single test cycle included process of alternate heating and cooling - Fig. 1. Recurrent influence of temperature stimulated the impact of aircraft on airfield pavements. The assumed heating and cooling time corresponded to the time during which the aircraft effected the most frequently used airfield pavement within the area of Poland. Velocity of gas stream emitted during the test was $30 \mathrm{~m} / \mathrm{s}$.
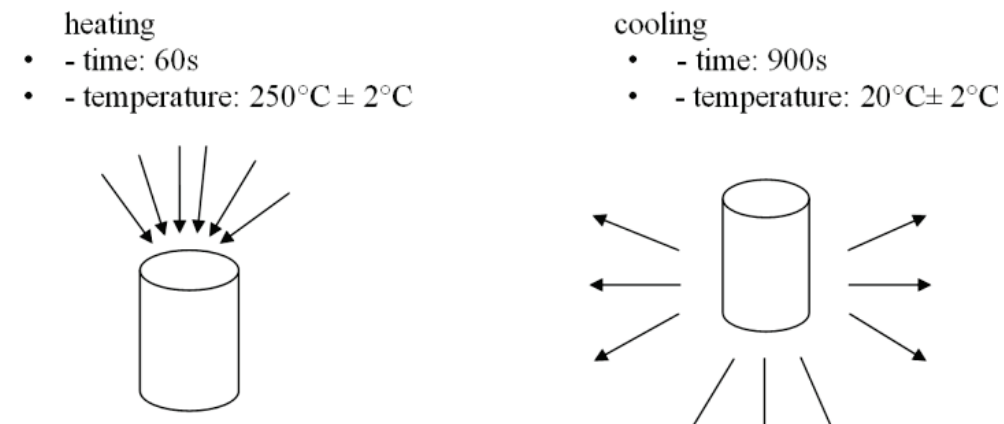

Fig. 1. Conditions assumed during the thermal research [1]

Using thermal analysis method, the selected concrete components were determined by means of quantitative method. The occurrence of crystalline stages was also determined using X-ray diffraction method.

Internal structure of concrete composite was also assessed. Scanning electron microscope was used for this purpose. Fresh fractures were performed taking concrete samples; the preparation surface subject to SEM observations was not less than $1.0 \mathrm{~cm}^{2}$. The extent of magnification was from 200x to $100000 x$. Chemical microanalyses of selected sections in concrete composite were performed, as well. The results obtained during the first stage served as the basis for the analysis of similarity of distance courses of analysed concretes [4].

\section{Research materials}

The designed aggregate mixes of series BM complied with the requirements of [5]. The aggregate compositions of the designed mixes were considered as good grain size distribution of airfield pavements. Composition of concrete included:

- cement [6] in the quantity of $325 \mathrm{~kg} / \mathrm{m}^{3}$,

- sand in the quantity of $390 \mathrm{~kg} / \mathrm{m}^{3}$,

- granite grit fraction $2 / 8 \mathrm{~mm}$ in the quantity of $510 \mathrm{~kg} / \mathrm{m}^{3}$,

- granite grit fraction $8 / 16 \mathrm{~mm}$ in the quantity of $430 \mathrm{~kg} / \mathrm{m}^{3}$,

- granite grit fraction $16 / 32 \mathrm{~mm}$ in the quantity of $442 \mathrm{~kg} / \mathrm{m}^{3}$,

- water [7] in the quantity of $148 \mathrm{~kg} / \mathrm{m}^{3}$,

- air entraining agent $-1.74 \mathrm{~kg} / \mathrm{m}^{3}$,

- plasticizing admixture $-0.63 \mathrm{~kg} / \mathrm{m}^{3}$,

- ceramic modifier of grain size distribution $0 / 2 \mathrm{~mm}$ in the amount of $45 \mathrm{~kg} / \mathrm{m}^{3}$.

The obtained concrete test results after 28 days of curing (BM) and subject to 50 forced thermal loads $\left(\mathrm{WBM}_{50}\right)$ were presented in Tab. 1. 
Tab. 1. Parameters of concretes

\begin{tabular}{|c|c|c|c|c|}
\hline \multicolumn{2}{|c|}{ Parameters } & Unit & BM & $\mathrm{WBM}_{50}$ \\
\hline \multirow{2}{*}{$f_{c}$} & $\bar{X}$ & $\mathrm{MPa}$ & 73.2 & 84.3 \\
\cline { 2 - 5 } & $\sigma$ & $\mathrm{MPa}$ & 1.436 & 1.392 \\
\hline
\end{tabular}

\section{Tests results and their analysis}

Pursuant to observations of fracture of BM (Fig. 2) and WBM 50 (Fig. 3) concrete series, it was proved that, internal structure changed. Differences in the surface zone were determined. In case of crystallization, there is diversification within the area of cement matrix, contact area between cement matrix and aggregate grains and in case of porosity characteristics of both concretes. Crystallization of cement matrix was also different. The accumulation of calcium carbonates in the cement matrix was determined. In case of $\mathrm{WBM}_{50}$ concrete, numerous hydrated calcium silicates type C-S-H crystallized. Moreover, in case of BM concrete, the contact areas with aggregate grains were still continuous.
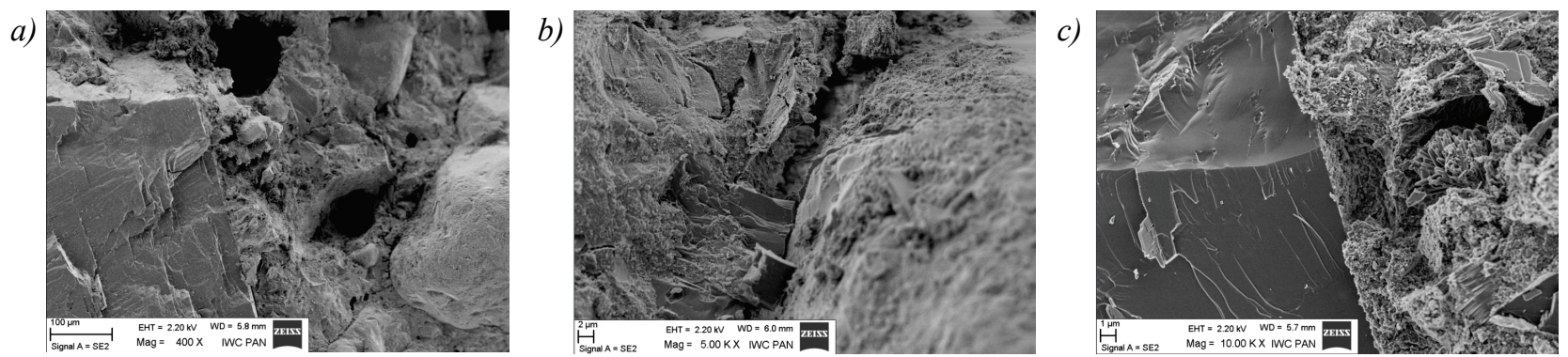

Fig. 2. Internal microstructure of BM concrete in selected sections: a) cement matrix, b)contact area between fine aggregate and cement matrix $x_{t}$ and c) contact area between granite aggregate and cement matrix

a)

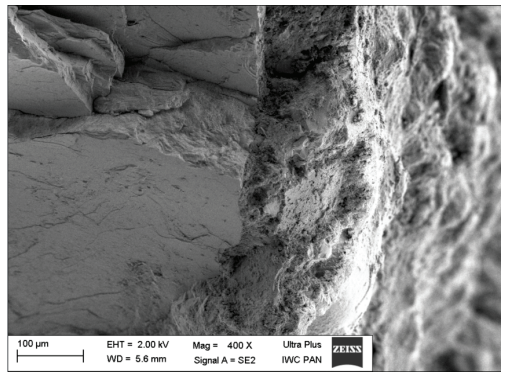

b)

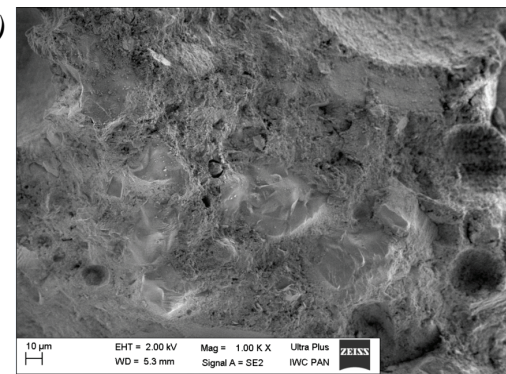

c)

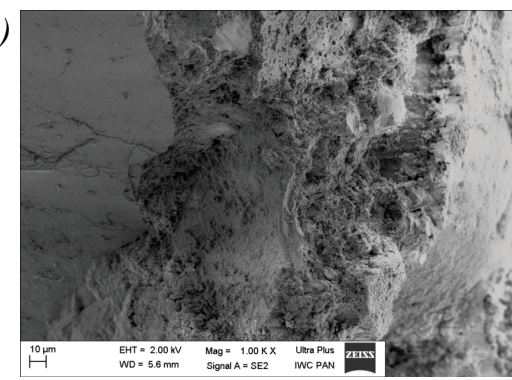

Fig. 3. Internal microstructure of WBM ${ }_{50}$ concrete in selected sections: a) cement matrix, b) contact area between fine aggregate and cement matrix $x_{t}$ and c) contact area between granite aggregate and cement matrix
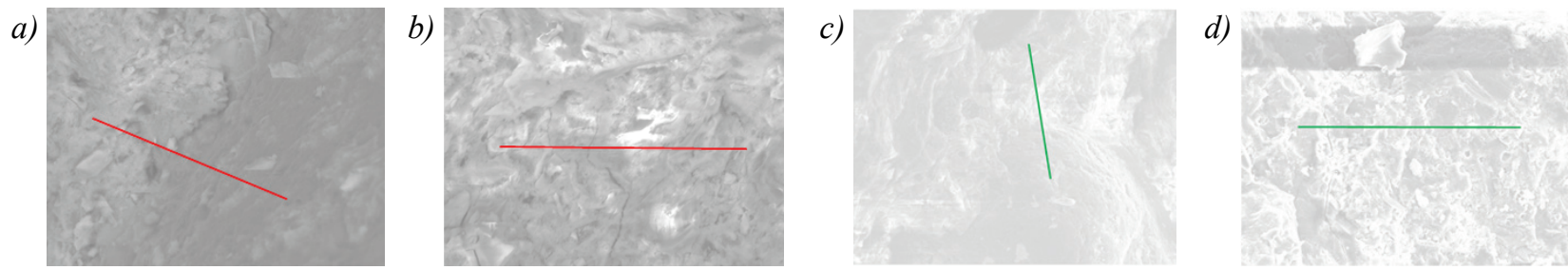

Fig. 4. Exemplary microanalysis of BM concrete (a-contact area between fine aggregate grains and cement matrix, $b$-cement matrix) and WBM $M_{50}$ concrete $(c$ - contact area between

fine aggregate grains and cement matrix, $d$-cement matrix)

Data obtained as a result of chemical microanalysis (average values of 6 analyses) of concretes was subject to similarity analysis - Fig. 4. As an input sequence in similarity analysis, $\mathrm{WBM}_{50}$ characteristics values obtained as $\mathrm{w}$ result of microanalysis of $\mathrm{BM}$ concrete series were assumed. 
The data, which reflect the percentage of selected elements in one of BM reference concrete sections, play the role of target sequence, which input sequence is compared with. Basic input sequence characteristics were presented in Tab. 2, while Fig. 5 presents the original form of input and target sequence.

Tab. 2. Input sequence characteristics in case of the selected element (carbon) within cement matrix section

\begin{tabular}{|c|c|c|c|c|c|}
\hline Variable & A number of observations & Minimum & Maximum & Mean & Standard deviation \\
\hline WBM $_{50}$ & 64 & 0.00 & 12.95 & 6.08 & 3.014 \\
\hline
\end{tabular}

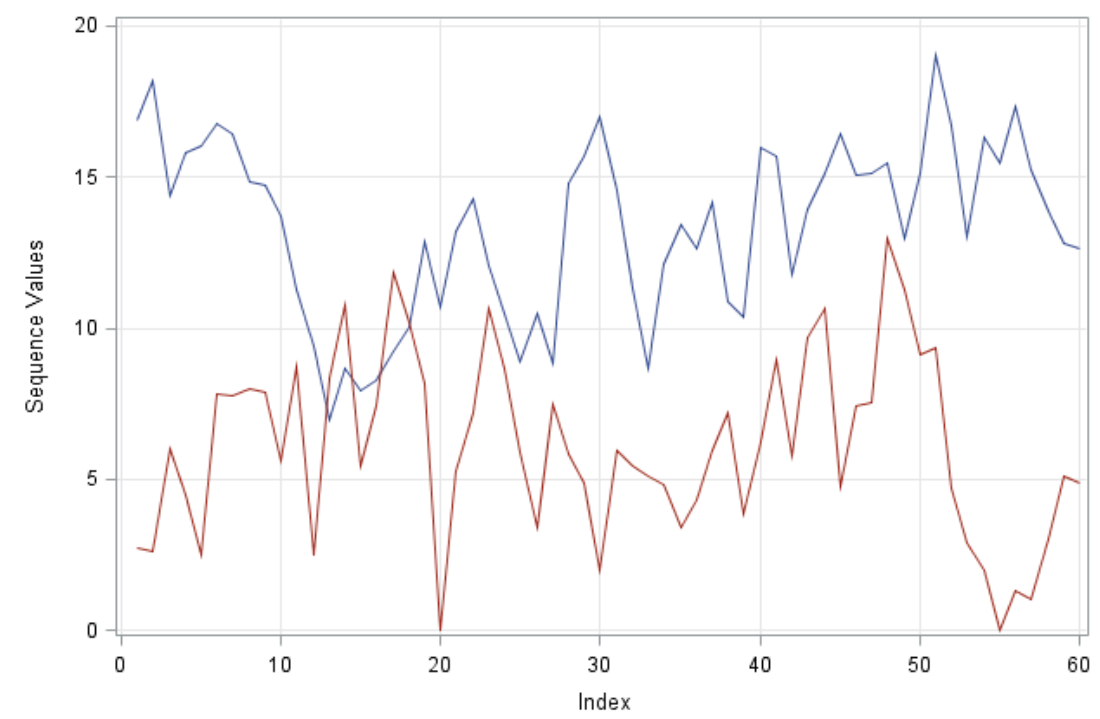

Fig. 5. Distance courses of original input sequence (red) and target sequence (blue)

In general case, the analysed courses were represented as $\left(x_{1}, x_{2}, \ldots, x_{n x}\right)$ for input sequence and $\left(y_{1}, y_{2}, \ldots, y_{n y}\right)$ for target sequence. As a record intended for comparison of input value $x_{i}$ and target value $y_{j}$, the absolute value of difference $x_{i}-y_{j}$ was assumed. In case of input and target sequences $n_{x} \times n_{y}$ of the distance between all possible pairs of elements of these sequences were calculated. The path was determined, which leads from the least average distance along the path. Fig. 5 presents the route of such path in case of the considered sequences. Relocation along the diagonal means direct influence between the target and input sequence. Motion along vertical path refers to the compression of target sequence with respect to input sequence, while the motion along the horizontal path - expansion of the target sequence with respect to input sequence. Expansion of a single value of target sequence takes place when it refers to more than one value of input sequence. Statistics concerning the path present the amount of compression and expansion of target sequence with respect to input sequence.

Distances were determined (Fig. 7) between the values of input and target sequences along the optimal path. Path indexes are placed on the axis of abscissa. Bold horizontal line refers to the average distance; the two remaining horizontal lines refer to distances, which differ from the average one by one or two standard deviations. Fig. 8 presents distance histogram between input and target sequences along optimal path with the indicated Gauss's curve and nuclear density curve.

According to the conducted analysis, similarity index was obtained between the input and target sequences along the optimal path, which is 3.668 .

Figure 9 presents the distance between values of input and target sequences along the optimal path. Path indexes are located on the axis of abscissa. Fig. 10 presents histogram of distance between standardized input and target sequences along optimal path with the indicated Gauss's curve and nuclear density curve. 


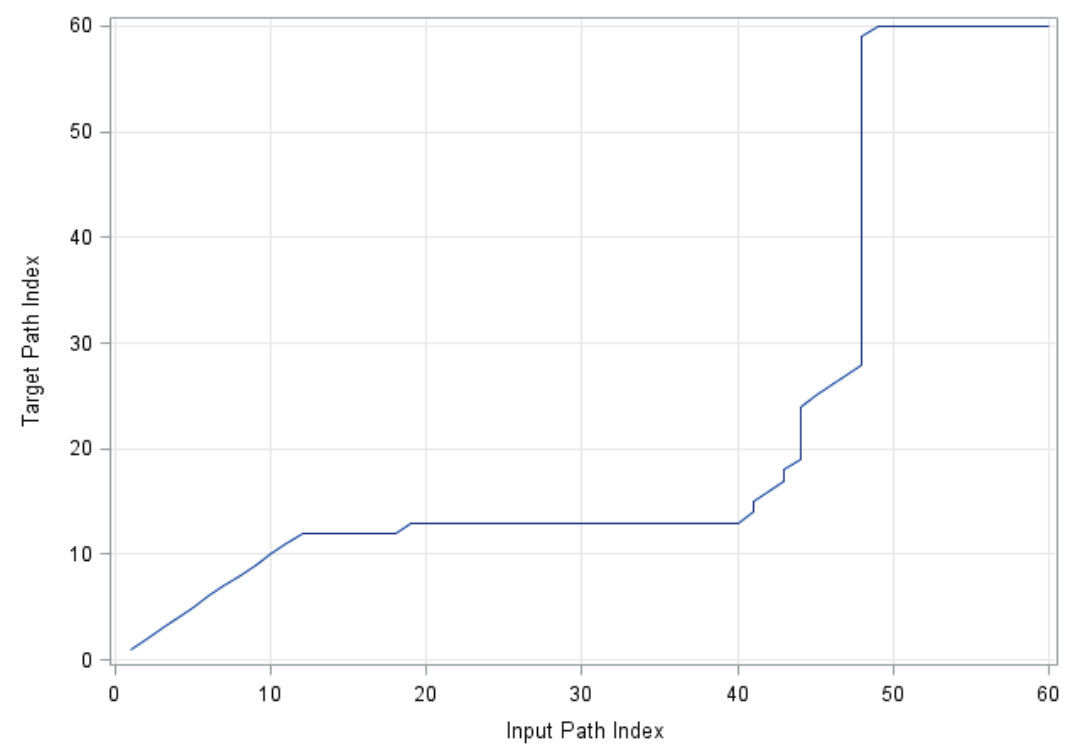

Fig. 6. Path leading to the smallest distance between the input and target sequences

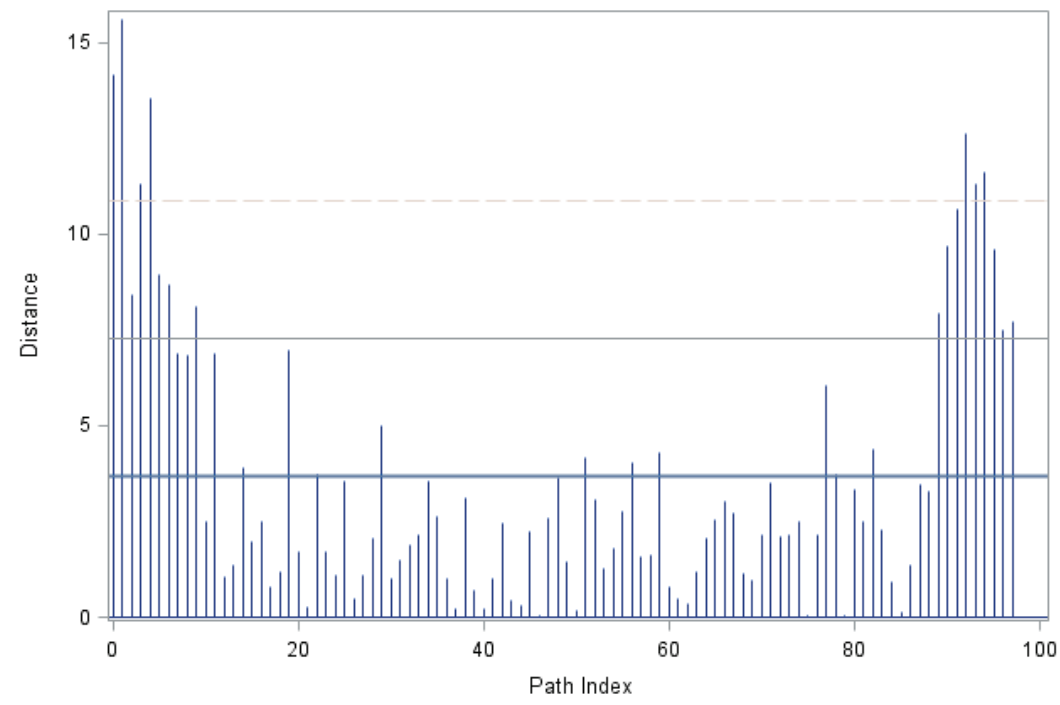

Fig. 7. Distance between the input and target sequences along optimal path

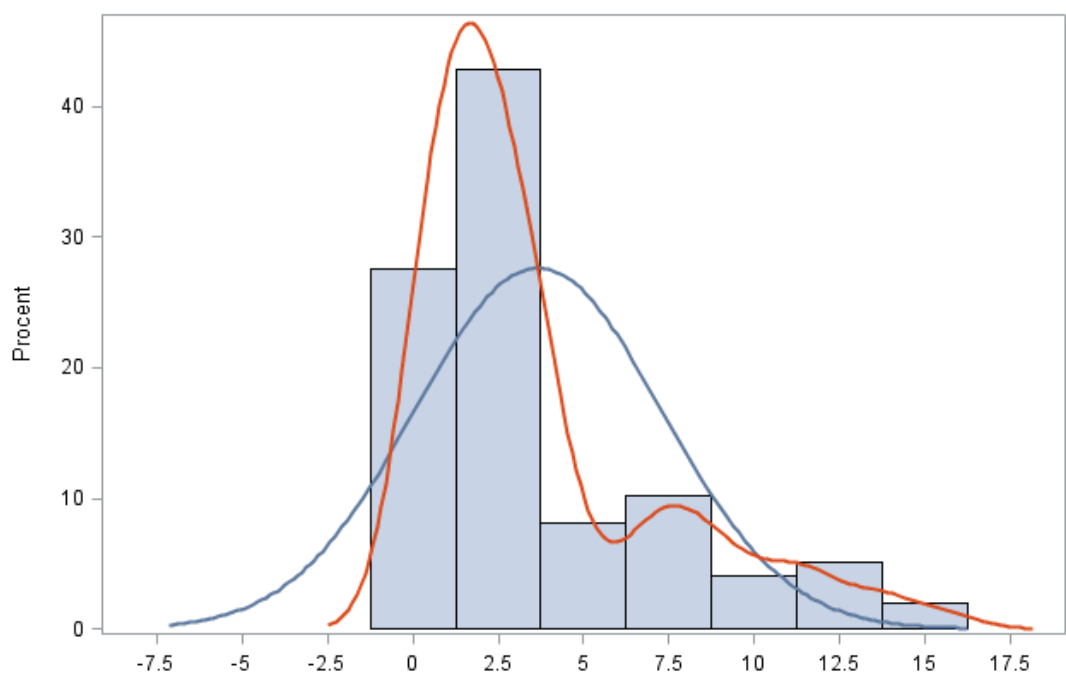

Fig. 8. Histogram of distance between input and target sequences along optimal path with indicated Gauss's curve (blue) and nuclear density curve (red) 


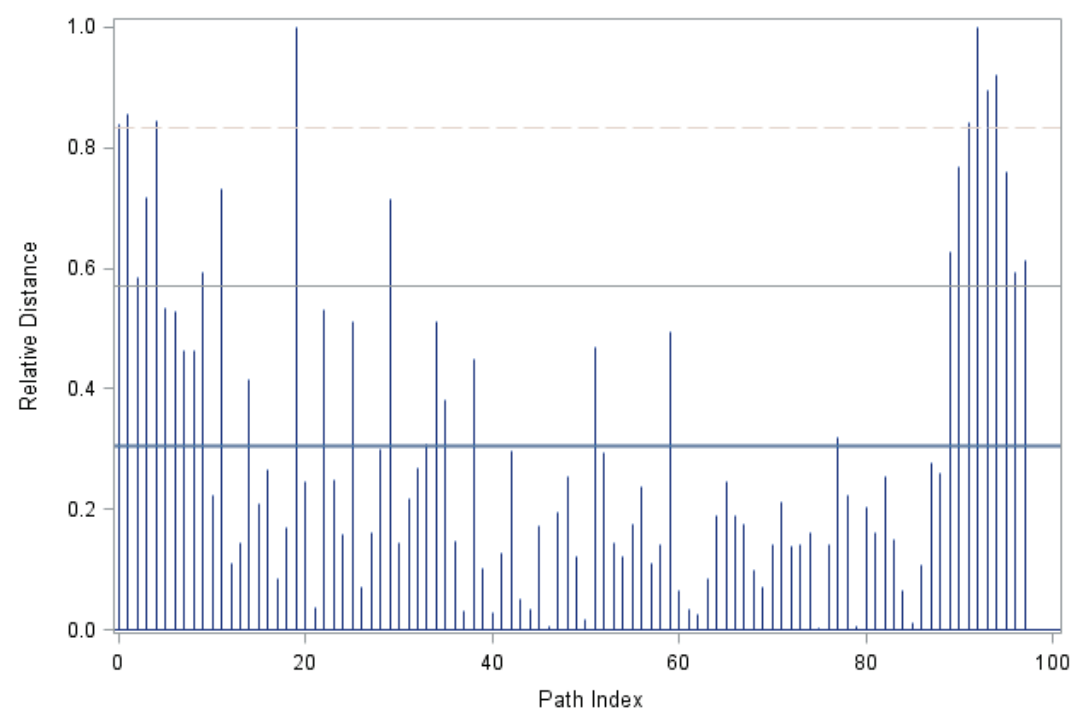

Fig. 9. Diagram of distance between standardized input sequence and standardized target sequence along optimal path

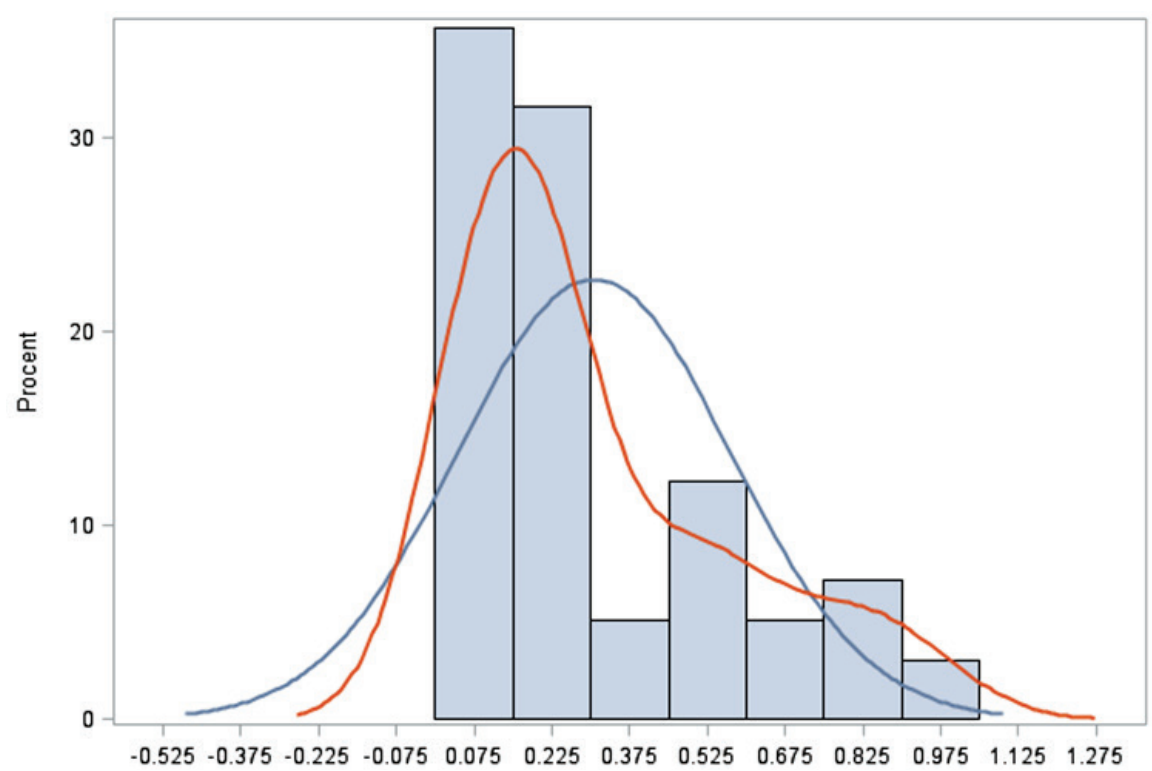

Fig. 10. Histogram of distance between standardized input sequence and standardized target sequence along optimal path with the indicated Gauss's curve (blue) and nuclear density curve (red)

The final effect of the conducted analysis was to define similarity index between input and target sequences along the optimal path, which is 0.543 .

The scope of the conducted analyses included diversification in terms of content of 10 chemical elements (carbon $-\mathrm{C}$, oxygen $-\mathrm{O}$, aluminum $-\mathrm{Al}$, silicon $-\mathrm{Si}$, sulphur $-\mathrm{S}$, potassium $-\mathrm{K}$, calcium $-\mathrm{Ca}$, iron $-\mathrm{Fe}$, sodium $-\mathrm{Na}$, magnesium $-\mathrm{Mg}$ ) in four various areas (matrix, matrixgranite, matrix-quartz, matrix-void). So far, range of chemical microanalysis with the use of formal similarity analysis of the obtained data has been conducted for concrete BM [2] and concrete BM after 200 cycles of frost resistance [3]. Similarity indexes included in Tab. 3 were obtained analogically, as described above. These indexes allow assessing independently the similarity of each concrete with respect to contents of individual elements in the considered areas.

According to the obtained similarity indexes, diagrams presenting ,proximity” of distance courses of the analysed concretes were prepared, with respect to reference concrete in terms of contents of elements in matrix and contact areas with quartz, and granite grains and air voids. For this purpose, the polygon method was used, where the shape and size of the result polygons, 
in minor extent, depend on the order of attributes. The number of sides of individual polygons equals the number of attributes used to specify objects.

Tab. 3. The list of similarity indexes $w_{p}$ for selected areas

\begin{tabular}{|c|c|c|c|c|c|c|c|c|c|}
\hline \multicolumn{1}{|c|}{ element } \\
\hline $\mathrm{C}$ & $\mathrm{O}$ & $\mathrm{Al}$ & $\mathrm{Si}$ & $\mathrm{S}$ & $\mathrm{K}$ & $\mathrm{Ca}$ & $\mathrm{Fe}$ & $\mathrm{Na}$ & $\mathrm{Mg}$ \\
\hline \multicolumn{10}{|c|}{ cement matrix } \\
\hline 0.543 & 0.436 & 0.335 & 0.526 & 0.758 & 0.498 & 0.414 & 0.344 & 0.783 & 0.689 \\
\hline \multicolumn{8}{|c|}{ cement matrix - air void } \\
\hline 0.323 & 0.480 & 0.467 & 0.441 & 0.315 & 0.561 & 0.511 & 0.621 & 0.543 & 0.481 \\
\hline \multicolumn{8}{|c|}{ cement matrix - quartz aggregate } \\
\hline 0.490 & 0.476 & 0.405 & 0.358 & 0.511 & 0.411 & 0.416 & 0.334 & 0.772 & 0.702 \\
\hline \multicolumn{8}{|c|}{ cement matrix - granite aggregate } \\
\hline 0.887 & 0.759 & 0.699 & 0.702 & 0.000 & 0.665 & 0.785 & 0.737 & 0.000 & 0.000 \\
\hline
\end{tabular}

In order to create polygons, values of each attribute were arranged and then the length of radii indicating vertices of individual polygons was calculated. The object of the minimum attribute value corresponds with the shortest radius towards this attribute. The object of the greatest attribute value had the longest radius. The remaining values of attributes were converted linearly within the length of radii coming from the centre of polygon towards relevant attributes. Values of the first attribute were presented on the radius of Ox axis direction. Values of the next attributes are located on the subsequent radii, counted from the first one counter-clockwise. Over the radius corresponding with the first attribute, there is the radius referred to the second attribute and under thereof - to the last attribute. Shape and size of a single polygon reflects how a given object is presented in comparison with other objects described by means of the same attributes. Attributes are similarity indexes of distance courses of concrete and reference concrete for subsequent elements in the defined area. Smaller polygon proves higher similarity of concrete to the reference concrete.

Tab. 4. The polygon method for data prior standardization (a) and data after standardization (b)

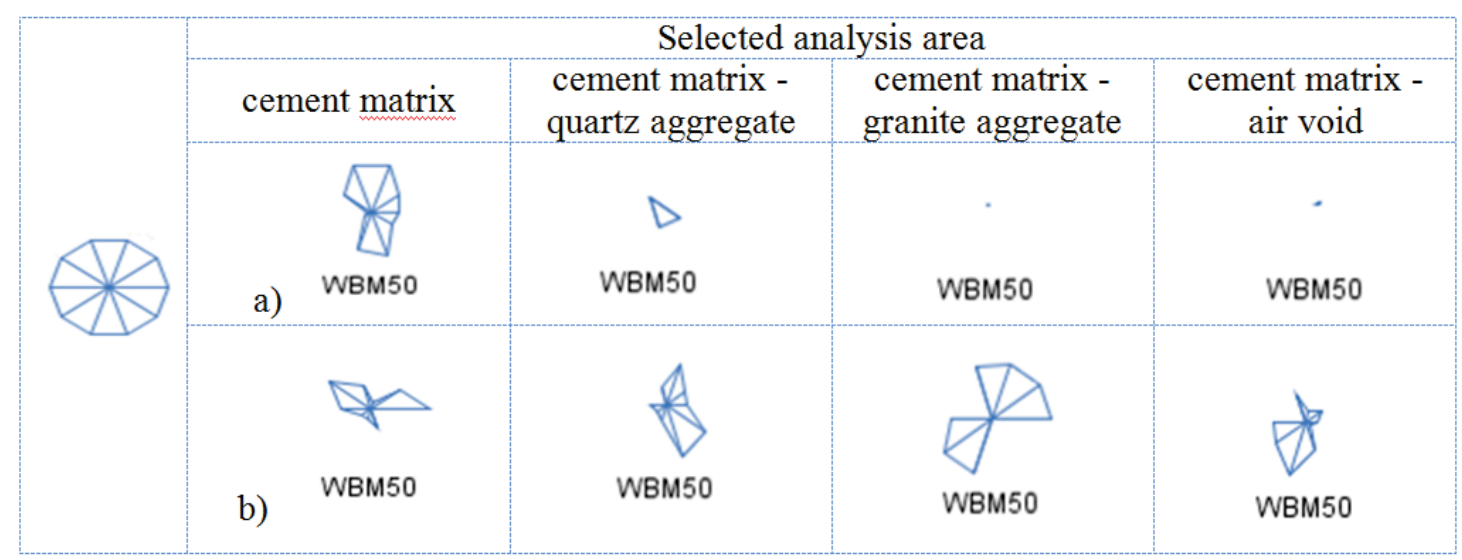

Based on the obtained distance courses (Tab. 3), it was proved that the influence of results standardization is a significant factor.

In case of data without standardization (Tab. 3a), the contact area between the air void and cement matrix and the contact area between the granite aggregate and cement matrix, have the most similar distance courses to the reference concrete. The highest diversification was proved in case of cement matrix. 
In the event of data subject to standardization (Tab. 3b), the most significant differences were found within the contact area between the cement matrix and granite aggregate grains. The remaining contact areas prove higher similarity of distance course with respect to BM concrete; however, they clearly differ from thereof.

\section{Conclusions}

According to the conducted laboratory tests, the following conclusions have been reached:

1) Application of ceramic additive to the cement mix influences the changes of BM concrete ultimate compressive strength (increase of resistance $\mathrm{WBM}_{50}$ concrete by $23.9 \mathrm{MPa}$ in comparison of concrete of concrete BM).

2) Characteristics of internal microstructure of WBM concrete after 50 thermal forced cycles with respect to the comparative concrete was changed.

3) According to the analysis of the obtained distance courses for the concrete $\mathrm{WBM}_{50}$ it was proved that the most significant differences occur within the contact area between the cement matrix and fine aggregate grains.

\section{References}

[1] Linek, M., Application of ceramic dust as a modifier reducing the extent of rheological deformations in airfield pavement concrete, MATEC Web of Conferences 163, 2018.

[2] Linek, M., Application of similarity method of distance courses describing the elements content in concrete intended for airfield pavements, Journal of KONES Powertrain and Transport, Vol. 24, No. 4, pp. 385-392, 2017.

[3] Linek, M., Application of similarity method of distance courses describing the elements content in cement concrete after frost resistance test, Journal of KONES Powertrain and Transport, Vol. 25, No. 3, pp. 331-337, 2018.

[4] Linek, M., Surface concrete with improved parameters of physical and mechanical on the loads caused by forced temperature, PhD Thesis, Kielce 2013.

[5] NO 17-A204:2015, Airfield concrete pavements - Requirements and test methods for cement concrete pavements, Polish Standard.

[6] PN-EN 197-1:2012, Cement, part 1: Composition, specyfications and conformity criteria for common cements, Polish Standard.

[7] PN-EN 1008:2004, Mixing water for concrete - Specification for sampling, testing and assessing the suitability of water, including water recovered from processes in the concrete industry, as mixing water for concrete, Polish Standard.

[8] PN-EN 12390-1:2013, Testing hardened concrete - Part 1: Shape, dimensions and other requirements for specimens and moulds, Polish Standard.

[9] PN-EN 12390-2:2011, Testing hardened concrete - Part 2: Making and curing speciments for strength tests, Polish Standard.

[10] PN-EN 12390-3:2011, Testing hardened concrete - Part 3: Compressive strength of test specimens, Polish Standard.

Manuscript received 27 August 2019; approved for printing 20 December 2019 